\title{
Luminance Calibration and Linearity Correction Method of Imaging Luminance Measurement Devices
}

\author{
Da riusz Czyżewski, ${ }^{1}$ and Irena Fryc ${ }^{* 2}$ \\ ${ }^{I}$ Electrical Power Engineering Institute, Warsaw University of Technology, Koszykowa 75, 00-662 Warszawa \\ ${ }^{2}$ Faculty of Electrical Engineering, Bialystok University of Technology, Wiejska 45d, 15-351Bialystok
}

Received March 23, 2021; accepted April 07, 2021; published June 30, 2021

\begin{abstract}
This paper shows that the opto-electrical characteristic of a typical CCD based digital camera is nonlinear. It means that a digital electric signal of the camera CCD detector - is not a linear function of the luminance value on the camera lens. The opto-electrical characteristic feature of a digital camera needs to be transformed into a linear function if this camera is to be used as a luminance distribution measurement device known as Imaging Luminance Measurement Device (ILMD). The article presents the methodology for obtaining the opto-electrical characteristic feature of a typical CCD digital camera and focuses on the non- linearity correction method.
\end{abstract}

The imaging luminance measurement device(ILMD) is also known as a luminance meter [1-7], an array (or matrix or digital) luminance meter [8-10], a multichannel digital luminance meter [11], a luminance mapper [12], a video photometer [13], a luminance camera [14-17] or a spatial luminance profile device [18]. It is important to highlight the fact that the traditional spot luminance measurement device (LMD) gives the user inform ation only about one spatially a veraged luminance value of light sources or illuminated surfaces. Howe ver, the user of ILMD gets the luminance image [19] which gives information about spatial distribution of luminance (see Figure 1). It is because ILMD measures object luminance at many points at the same time.

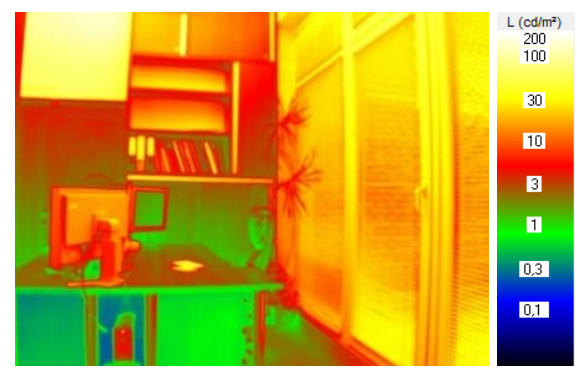

Fig. 1. Example of ILMD luminance distribution measurement.

The schematic diagram of a typical ILMD construction ba sed on a n ordinary digital camera is presented in Fig. 2 . It consists of a lens system, $V(\lambda)$ correction filter, CCD sensor with an amplifier, low noise analog electronics, $\mathrm{A} / \mathrm{D}$ conversion and digital da ta transfer.

*E-mail: i.fryc@pb.edu.pl

http://www.photonics.pl/PLP

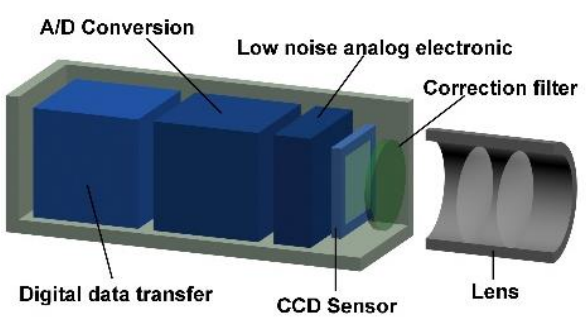

Fig. 2. The schematic diagram of ILMD.

This kind of device needs to be calibrated. It mean s that the rela tion ship between the values of quantities indicated by a CCD sensor and the corresponding valu es re a lized by luminance standard needs to be set. The characteristics of optical input signal (luminance) conversion into an output digital electrical signal were tested to check whether it is possible to use the classicalCanon QV-5700 digital camera (see parameters at Table 1) to measure luminance distributions. The tested digital ca mera has 3 channels for converting an optical signal into an electrical one, i.e., RGB.

Table.1. Technical parameters of Canon QV-5700 digital camera.

\begin{tabular}{|c|c|}
\hline Parameter & Value \\
\hline Sensor type & CCD $1 / 1.8$ \\
\hline Effective pixels & 5.0 megapiksel $(2560 \times 1920)$ \\
\hline Lens Aperture & $\mathrm{f} / 2.0-\mathrm{f} / 2.5$ to $\mathrm{f} / 8.0$ \\
\hline Shutter Speeds & $60 \mathrm{~s}-1 / 1000 \mathrm{~s}$ \\
\hline Sensitivity & auto, ISO $: 50,100,200,400,800$ \\
\hline Metering & Multi-pattern, Center-weighted average, Spot \\
\hline Exposure Compensation & \pm 2 EV in $1 / 3$ EV steps \\
\hline Autobracketing & AEB \\
\hline Manual focus & Yes \\
\hline Focus lock & Yes \\
\hline
\end{tabular}

Figure 3 shows the luminance standard set-up ty pically used for the calibration of ILMDs. It is based on the luminance standard OL 455. The parameters characterizing that standard are presented in Table 2 . The results of calibration allow to assign the values of standard luminance to the values measured by ILMD. In the case of ILMDs, the luminance unit is candela per square meter. 


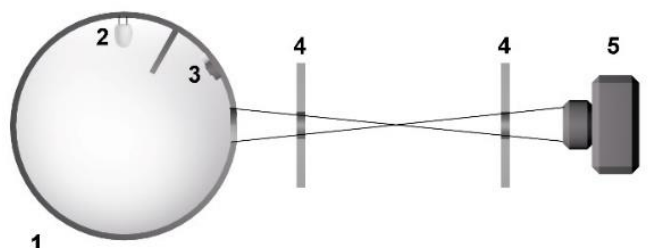

Fig. 3. The set-up used for the calibration of Canon QV-5700 digital camera, where: 1 - photometric sphere, 2 -reference light source,

3 -photometric head, 4 - shutters, 5 - digital camera.

Table. 2. Technical parameters of OL 455 standard.

\begin{tabular}{|l|c|}
\hline \multicolumn{1}{|c|}{ Parameter } & Value \\
\hline $\begin{array}{l}\text { Luminance } \\
\text { Uncertainty }\end{array}$ & $\begin{array}{c}\text { (@2856 K, } 90 \% \text { max. luminance) } \pm 0.5 \% \text { relative } \\
\text { to NIST }\end{array}$ \\
\hline $\begin{array}{l}\text { Luminance } \\
\text { Stability }\end{array}$ & @ $2856 \mathrm{~K}$, Short Term $\pm 0.5 \%$ \\
\hline $\begin{array}{l}\text { Luminance } \\
\text { Range }\end{array}$ & $0 \div 30000 \mathrm{~cd} / \mathrm{m}^{2}$ \\
\hline
\end{tabular}

The measured input-output characteristics of Canon QV-5700 digitalcamera showed significant nonlinearities in the processing of an optical signal into an electrical one. The output signal from this digital ca mera can be read for three channels: Red (R), Green $(G)$ and Blue (B). The examples of measurement results for the $\mathrm{R}$ channel are shown in Fig. 4.

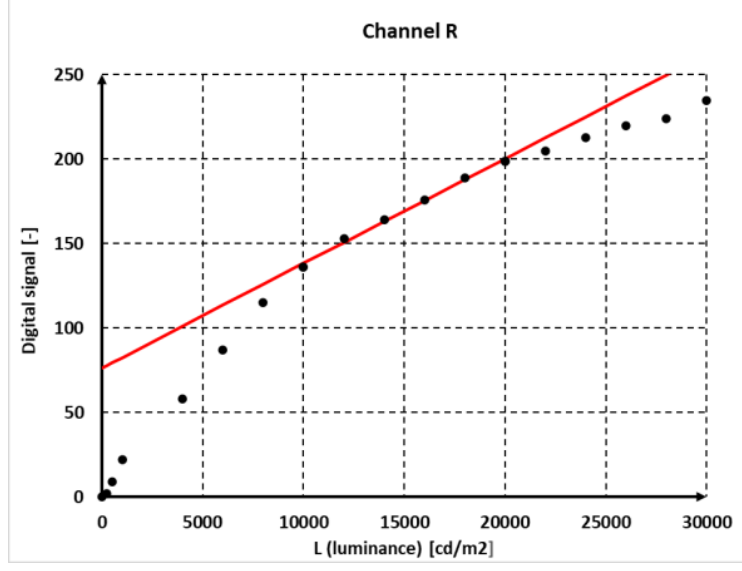

Fig. 4. The measured input-output characteristics of Canon QV-5700 digital camera.

In measuring practice, the calibration of a measuring instrument does not ensure the perfect linearity of its input-output characteristics. Therefore, the international measurements standards introduce an error $\mathrm{f}_{3}$ as a measure of quality of the ILMD meter. The error $\mathrm{f}_{3}$ is calculated according to the formula (1) [20]. Ba sed on the $f_{3}$ value, the ILMD class is determined. According to the information provided by DIN 5032-7:2017 [18], the se classes ca $n$ be categorized a s shown in Table 3 . The other categorization methods are given by the EU standard EN 13032-1:2004 [19] (Table 4) and by CIE 231:2019 technical report [20] (Table 5).

$$
f_{3}=\left|\frac{Y}{Y_{\max }} \frac{X_{\max }}{X}-1\right|
$$

where: $Y$ is describing the output signalof a luminance meter; $X_{\max }$ is used for the input value corre sponding to the maximum output signal $Y_{\max }$.

Table. 3. Luminance meters classification according to DIN 50327:2017 standard.

\begin{tabular}{|c|c|c|c|c|c|}
\hline Index & Symbol & Class L & Class A & Class B & Class C \\
\hline Linearity & $f_{3}$ & $0.2 \%$ & $1.0 \%$ & $2.0 \%$ & $5.0 \%$ \\
\hline
\end{tabular}

Table. 4. The luminance meters classification defined by EN 13032 1:2004 standard.

\begin{tabular}{|c|c|c|}
\hline Index & Symbol & Maximal Value \\
\hline Linearity & $f_{3}$ & $0.2 \%$ \\
\hline
\end{tabular}

Table. 5. Luminance meters classification defined by the CIE 231:2019 technical report.

\begin{tabular}{|c|c|c|c|c|c|}
\hline Index & Symbol & Class 4 $^{*}$ & Class 3 $^{*}$ & Class 2 $^{*}$ & Class 1 $^{*}$ \\
\hline Linearity & $f_{3}$ & $0.2 \%$ & $1.0 \%$ & $2.0 \%$ & $5.0 \%$ \\
\hline
\end{tabular}

By a nalyzing data showed in Figure 4, it wa s found that there are three areas for rela tively linea roperation of this digital camera. They can be distinguished as follows: the first one - from $0 \mathrm{~cd} / \mathrm{m}^{2}$ to $10000 \mathrm{~cd} / \mathrm{m}^{2}$, the second one from $10000 \mathrm{~cd} / \mathrm{m}^{2}$ to $20000 \mathrm{~cd} / \mathrm{m}^{2}$, a nd the third one from $20000 \mathrm{~cd} / \mathrm{m}^{2}$ to $30000 \mathrm{~cd} / \mathrm{m}^{2}$ (see Figure 5).

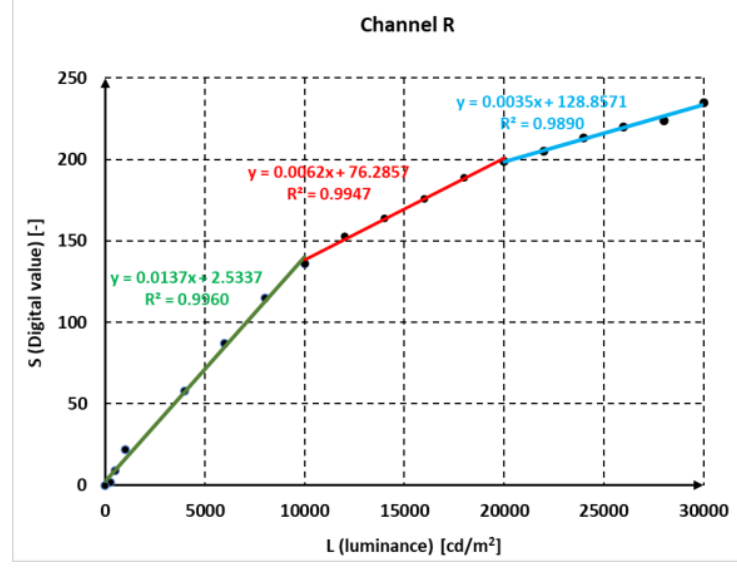

Fig. 5. The approximation of Canon QV-5700 digital camera inputoutput characteristics by three different linear functions

Another way to approximate the camera in put-output characteristics is to use the polynomial function. The polynomial functions (order 2, 3 and 4) describing an output signal from the red $(\mathrm{R})$ channel of this digital camera are presented in Figs. 6, 7 and 8, respectively. The polynomial equation (trend line) and factor $\mathrm{R}^{2}$ are provided in each Figure (Fig. 6, 7, and 8). However, the $\mathrm{R}^{2}$ for each of these polynomials is greater than 0.99 . It is worth noting that using a $2^{\text {nd }}$ order polynomial for this application is not recommended because it causes significant deviations for the luminance of $30000 \mathrm{~cd} / \mathrm{m}^{2}$. 


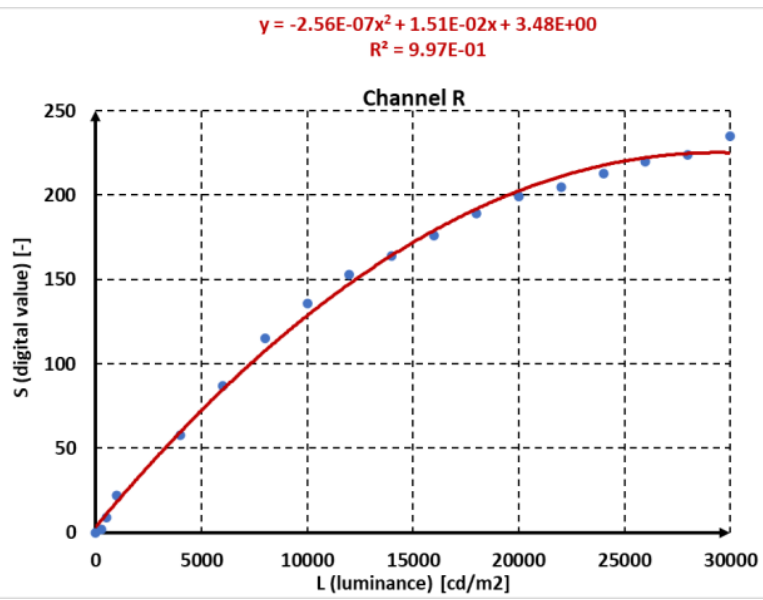

Fig. 6. The approximation of Canon QV-5700 digital camera inputoutput characteristics by a $2^{\text {nd }}$ order polynomial.

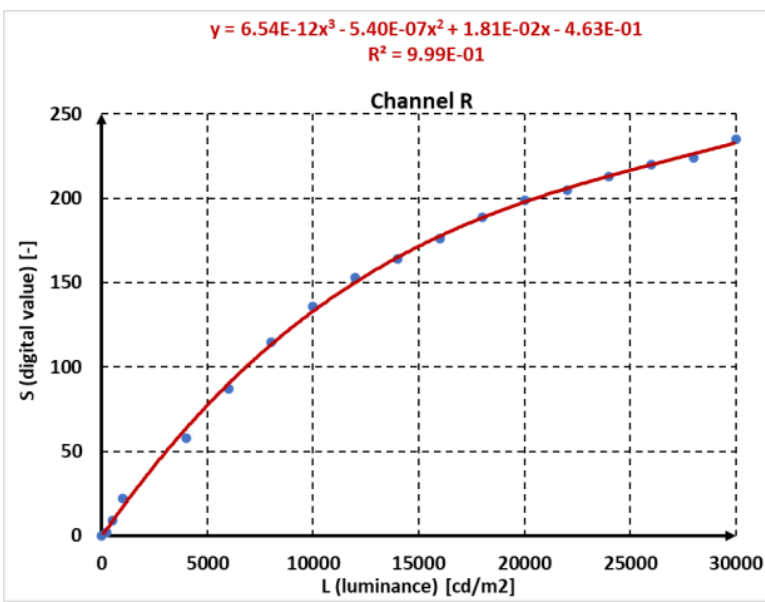

Fig. 7. The approximation of Canon QV-5700 digital camera inputoutput characteristics by a $3^{\text {rd }}$ order polynomial.

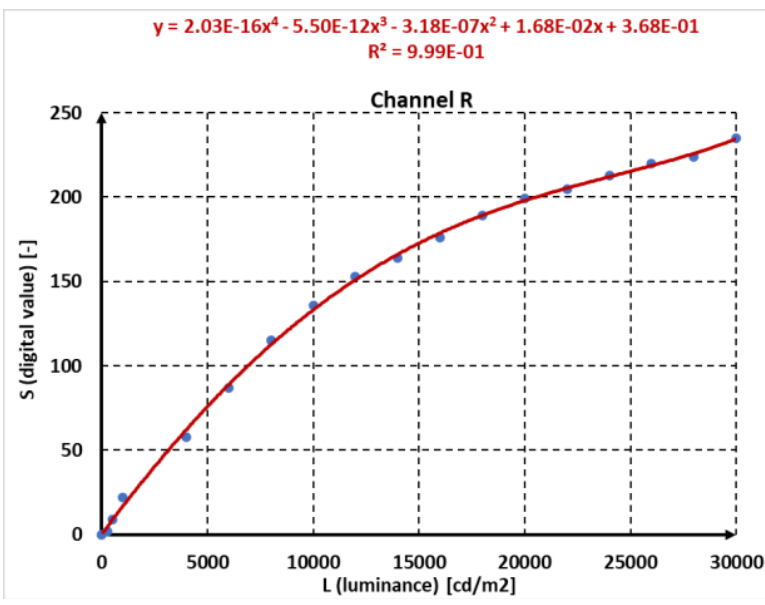

Fig. 8. The approximation of Canon QV-5700 digital camera inputoutput characteristics by a $4^{\text {th }}$ order polynomial.

To linearize the function of converting a light signal in to an electric one, the measurement data should be multiplied by the inverse function. Therefore, it is recommended to approximate the calibration points by at least a $3^{\text {rd }}$ order polynomial function (see Fig. 7 and Fig. 8), and then to determine the inverse function (Table 5). If the relation describing a given poly nomial function $\mathrm{S}(\mathrm{L})$ (where: $\mathrm{S}$ is Signal in digits, $\mathrm{L}$ is Luminance $\mathrm{cd} / \mathrm{m}^{2}$ ) is written (Eq. (2)), then the function inverse to a given function $\mathrm{S}(\mathrm{L})$ with respect to $\mathrm{L}$ will be the function $\mathrm{f}^{-1}(\mathrm{~S})$ described by the Eq. (3).

$$
\begin{gathered}
S=f(L) \\
L=f^{-1}(S)
\end{gathered}
$$

Table. 5. The ILMD input-output $\mathrm{S}=\mathrm{f}(\mathrm{L})$ characteristics approximation function and its inverse $\mathrm{L}=\mathrm{f}^{-1}(\mathrm{~S})$ polynomial.

\begin{tabular}{|c|c|}
\hline $\mathrm{S}=\mathrm{f}(\mathrm{L})$ & $\mathrm{L}=\mathrm{f}^{-1}(\mathrm{~S})$ \\
\hline $\mathrm{y}=6.54 \mathrm{E}-12 \mathrm{x}^{3}-5.40 \mathrm{E}-07 \mathrm{x}^{2}+$ & $\mathrm{y}=2.66 \mathrm{E}-03 \mathrm{x}^{3}-4.65 \mathrm{E}-01 \mathrm{x}^{2}+$ \\
$1.81 \mathrm{E}-02 \mathrm{x}-4.63 \mathrm{E}-01$ & $8.06 \mathrm{E}+01 \mathrm{x}-9.84 \mathrm{E}+01$ \\
\hline $\mathrm{y}=2.03 \mathrm{E}-16 \mathrm{x}^{4}-5.50 \mathrm{E}-12 \mathrm{x}^{3}-$ & $\mathrm{y}=-1.65 \mathrm{E}-06 \mathrm{x}^{4}+3.35 \mathrm{E}-03 \mathrm{x}^{3}-$ \\
$3.18 \mathrm{E}-07 \mathrm{x}^{2}+1.68 \mathrm{E}-02 \mathrm{x}+3.68 \mathrm{E}-$ & $5.87 \mathrm{E}-01 \mathrm{x}^{2}+8.91 \mathrm{E}+01 \mathrm{x}+$ \\
01 & $1.16 \mathrm{E}+02$ \\
\hline
\end{tabular}

The $5^{\text {th }}$ order polynomialfunction linearizing lu m inance mea surements (for RGB channels of this ca mera) a nd its inverse function are presented in the paper [24].

\section{References}

[1] D. Wüller, H. Gabele, SPIE 6502, 65020U (2007).

[2] P. Fiorentin, A. Scroccaro, IEEE Tr. Inst. Meas. 59, 5 (2010).

[3] M. Shpak, P. Kärhä, G. Porrovecchio, M. Smid, E. Ikonen, Meas. Sci. Technol. 25, 9 (2014).

[4] P. Fiorentin, P. Iacomussi, G. Rossi, IEEE Trans. Instr. Meas. 54, 1 (2005).

[5] I. Fryc, E. Czech, Proc. SPIE 5064, 2002 (2003).

[6] I. Fryc, Proc. SPIE 5064, 2002 (2003).

[7] I. Fryc, Optic. Engin. 40, 8 (2001).

[8] D. Czyzewski, Proc. IEEE Light. Conf. the Viseg. Count., Lumen V4 (2016).

[9] M. Sielachowska, D. Tyniecki, M. Zajkowski, VII. Light. Conf. the Viseg. Count., Lumen V4 (2018).

[10] W. Malska, H. Wachta, Proc. IEEE Light. Conf. the Viseg. Count., Lumen V4 (2016)

[11] T. Kruisselbrink, R. Dangol, A. Rosemann, Build. Envir. 138, (2018).

[12] A. Borisuit, M. Münch, L. Deschamps, J. Kämpf, J.-L. Scartezzini, Proc. SPIE 8485, 84850M (2012).

[13] I. Lewin, J. O'Farrell, Jour. of the Ill. Eng. Soc. 28, 1(1999).

[14] D. Czyzewski, Crystals 9, 12 (2019).

[15] K. Tohsing, M. Schrempf, S. Riechelmann, H. Schilke, G. Seckmeyer, Appl. Opt. 52, 8 (2013).

[16] D. Czyzewski, Proc. IEEE Light. Conf. the Vis. Coun., Lumen V4 (2016).

[17] A. de Vries, J. L. Souman, B. de Ruyter, I. Heynderickx, Y. A. W. de Kort, Build. Envir. 142, (2018).

[18] D. Silvestre, J. Guy, J. Hanck, K. Cornish, A. Bertoneet, Sci Rep 10, 13039 (2020).

[19] H. Wachta, K. Baran, M. Leśko, AIP Conf. Proc. 2078,(2019).

[20] Standard ISO/CIE 19476, (2014).

[21] Standard DIN 5032-7, (2017).

[22] Standard EN 13032-1, (2004).

[23] Technical Raport CIE 231, (2019)

[24] E. Czech, D. Czyzewski, Phot. Lett. Poland 13, 1 (2021). 